\title{
LA FAUNA SIMBÓLICA EN LOS CUENTOS DE JUAN RULFO
}

\author{
Carla'Victoria Jara Murillo
}

\begin{abstract}
RESUMEN
El objetivo principal de este artículo es el análisis de la simbología animal en los cuentos de El llano en llamas, de Juan Rulfo. Se hace un recorrido por los dieciséis relatos que componen el volumen para determinar el funcionamiento de una serie de imágenes, metáforas y símbolos de referentes animales que establecen una isotopía.
\end{abstract}

\begin{abstract}
The main objective of this article is to analyze the animal symbols in the short stories of Juan Rulfo's El llano en llamas. The sixteen stories are studied to determine the workings of a series of images, metaphors and symbols with animal refents that establish an isotopy.
\end{abstract}

\section{Introducción}

Antes de que surgiera el estructuralismo, por lo general los estudios sobre una obra literaria se concentraban, más que en la obra en sí misma, en la vida de su autor. También era frecuente hacer la alabanza de la obra en el más depurado estilo poético, pero sin que se estableciera un criterio objetivo de análisis. A finales del siglo pasado, este tipo de estudio literario entra en crisis, pero no es sino hasta avanzado el siglo XX y por influencia del estructuralismo desarrollado por Ferdinand de Saussure en el campo de la lingüística, que empieza a tomar forma lo que se denomina la "ciencia literaria", es decir, el análisis de una obra literaria según un método riguroso y objetivo.

En la década del sesenta es cuando toman gran auge los estudios literarios que utilizan métodos de análisis rigurosos: algunos estructuralistas, como los desarrollados por R. Barthes, Claude Bremont, Greimas, Genette, Todorov, y otros marxistas, como los propuestos por Goldman, Lukacs, Balibar y Macherey.

En el análisis estructuralista, la obra literaria se consideraba una estructura completa en sí misma, cuya existencia era independiente de su creador. La obra era vista como sistema 
y se le atribuía carácter inmanente, esto es, independiente. La vida del autor dejó de tener la relevancia que tradicionalmente había tenido y se dejó de hablar sobre ella.

Sin embargo, la moda de los análisis estructuralistas de la obra literaria también fue pasando: Barthes abandonó el estructuralismo; luego vino la teoría del texto de Julia Kristeva, posteriormente el deconstruccionismo, y con el hallazgo de la teoría dialógica de Mijail Bajtín se incorporan a la ciencia literaria múltiples niveles de análisis que, como sugiere María Amoretti, se abren en un abanico de lecturas posibles y se recogen de nuevo en una integración renovada de los varios aspectos de la obra literaria. Este aporte bajtiniano ha sido llamado "intertextualidad": "un develamiento de las capas implícitas más profundas en el fenómeno literario" (Amoretti 1992:7).

Esta breve referencia a la historia reciente de la crítica literaria me permito hacerla para señalar una vez más (cf. Jara 1987) la pertinencia de contar, al entablar diálogo con la obra literaria, con una intuición inicial por parte del lector, no solo permitida sino obligada, si queremos que el fenómeno literario sea válido como acto de habla, es decir, si ha de completarse el acto comunicativo con la concurrencia de la palabra del lector.

Uno de los problemas que suscitaba el análisis estructuralista de la obra literaria era precisamente el ya señalado carácter inmanente que se le atribuía a la obra. En el caso de Juan Rulfo, pareciera indispensable el contexto de su vida para entender uno de los aspectos esenciales de su obra: la muerte como hilo conductor, tanto en su novela Pedro Páramo como en los cuentos de El Llano en Llamas. Es en esta luz -el convencimiento de que la situación de producción real de una obra es un aspecto relevante para su comprensión- que incluyo aquí algunos datos sobre la vida de Rulfo y consideraciones útiles sobre El Llano en Llamas, en el contexto de la narrativa latinoamericana.

Como objetivo concreto, me interesa aquí un aspecto poco señalado de la obra de Rulfo: el de la simbología animal en los cuentos de El Llano en Llamas. En el presente artículo se hace un recorrido por los dieciséis relatos que componen el volumen para determinar el funcionamiento de una serie de figuras que establecen una isotopía, para utilizar un término de Greimas (1976), de referentes animales.

\section{Juan Rulfo}

Nació en Jalisco, México, en 1918, de nombre verdadero Juan Pérez Vizcaíno. Trabajó durante mucho tiempo en contaduría (y más tarde, habiendo estudiado también antropología social), en el Instituto Indigenista de México. Estuvo en Costa Rica en 1975, de cuya visita nos ha quedado una interesante entrevista realizada por el periodista Carlos Morales (1985).

Tenía seis años cuando su padre fue asesinado; poco después lo fueron también sus tíos. Era la época turbulenta de los años veinte. La Revolución Mexicana, iniciada en 1910, había dejado una gran estela de violencia especialmente en la zona rural de México.

Pasó la niñez en la hacienda de sus abuelos. En 1924 perdió a su padre: "lo mataron una vez cuando huía... y a mi tío lo asesinaron, y a otro y a otro.... y al abuelo lo colgaron de los dedos gordos, los perdió.... todos morían a los 33 años." (Juan Rulfo en Los narradores ante el público) Pocos años después se le murió su madre (Menton 1964: 85). 
Para Rulfo, el compromiso del escritor es con la cultura y no con la política; por ello ahonda en la problemática del campesino mexicano, y aunque se ha declarado como un escritor no comprometido políticamente (Morales 1985: 88), en su obra está siempre latente la denuncia de la violencia, la pobreza y la opresión del campesinado.

\section{El Llano en Llamas}

Enrique Anderson Imbert (1964: 330), historiador de la literatura hispanoamericana, dice de El Llano en Llamas: "Juan Rulfo amoldó la vida regional -con sus paisajes, sus nombres, sus palabras y sus situaciones de inocencia, crimen, adulterio y muerte- en los cuentos de El Llano en Llamas".

Con esto, Anderson Imbert nos define un Juan Rulfo simplemente criollista. Sin embargo, lo único de criollismo que se le puede señalar a Rulfo es la temática: la temática del criollo, del hombre rural. Pero en lo que concierne a su estilo, a su técnica narrativa, Rulfo se aleja muchísimo del criollismo tradicional, pariente muy cercano del costumbrismo.

Seymour Menton (1964: 94) dice que Rulfo no es criollista, sino más bien, cosmopolita, lo cual tampoco es apreciable en la obra de Rulfo. Para Menton, Rulfo es cosmopolita por su "sentido cósmico del protagonista más individualizado y su técnica experimental".

Siguiendo a Menton, las características de esta técnica experimental de Juan Rulfo son la profusión de escenas simultáneas y la presentación de varios puntos de vista, según el discurso vaya pasando de uno a otro personaje de la historia o al narrador. Para Menton, en esta técnica radica el cosmopolitismo de Rulfo.

Las innovaciones de los modernistas fueron aplicadas a temas nacionales por los primeros criollistas. Las innovaciones de los cosmopolitas ya se están aplicando también. Juan Rulfo, que publicó en 1953 su colección de cuentos El Llano en Llamas, es uno de los varios autores transicionales (hacia un neorrealismo) en cuyas obras se reconcilian los temas nacionales y la técnica experimental (Menton, op. cit., p. 95).

Para Carlos Fuentes, también mexicano, Rulfo, junto con Agustín Yáñez (Al filo del agua, La tierra pródiga) son los últimos expositores de "la temática documental de la Revolución Mexicana, procediendo a la mitificación de las situaciones, de los tipos y del lenguaje del campo" (Sainz de Robles 1949: 1078).

En la obra de Rulfo se pueden señalar también características del cubismo, a lo que alude Carlos Morales cuando en su entrevista le pregunta si hizo un dibujo geométrico para escribir la novela Pedro Páramo. Cubismo se denomina en literatura a la técnica de presentar la realidad desde distintos ángulos simultáneamente, por lo cual el tiempo aparece detenido o eternizado. Cabe recordar que la novela latinoamericana considerada cubista por excelencia es El Señor Presidente, de Miguel Ángel Asturias.

Por otra parte, los escritores latinoamericanos acusan influencias de los forjadores de la novela moderna, entre ellos Joyce, Proust, Faulkner. A Rulfo se le señalan principalmente las de los norteamericanos William Faulkner y Ernest Hemingway, específicamente en lo que se refiere a la técnica narrativa. Pero Rulfo personalmente no reconoce estas influencias, sino más bien la de algunos escritores nórdicos como Knut Hamsun y el ruso Boris Pigmiac. 
En síntesis, podemos decir que Rulfo combina la temática criollista, esto es, el tema nacional centrado en la vida del campesino mexicano, con la técnica experimental de la narrativa moderna, que incluye la dislocación del tiempo cronológico, el cambio de perspectiva gracias a la rotatividad del narrador, el monólogo interior, el devenir del pensamiento y el recuerdo, y con un ambiente propio de la narrativa neorrealista, es decir, los sectores sociales más desposeídos y desgarrados por la realidad miserable en la que viven.

\section{La fauna simbólica en los cuentos de El Llano en Llamas}

En esta enésima lectura de El Llano en Llamas me he detenido en un elemento que llama la atención porque aparece en todos los cuentos de las formas más diversas: el uso de las figuras referidas a animales. Esto porque me parece que tales figuras no son solamente parte de la descripción, sino que en muchas ocasiones establecen una relación simbólica con los personajes de cada cuento. La prominencia de la simbología animal varía de un cuento a otro. En algunos constituye un eje central en la caracterización de los personajes, en otros son apenas inserciones esporádicas en la caracterización de ambientes.

He dicho en la introducción que estas figuras referidas a animales establecen una isotopía a lo largo de los cuentos del volumen. Utilizo el término "isotopía" en un sentido muy amplio, sin mayor especificación técnica. Greimas (1970: 49) lo define como "un conjunto redundante de categorías semánticas que hace posible la lectura uniforme del relato". Robles Mohs (1983), quien hace un análisis de las isotopías de El Llano en Llamas, incluye las referencias animales en la isotopía que denomina "biogeográfica":

\footnotetext{
La flora y la fauna, como recursos referenciales de delimitación regional y climatológica, adquieren relevancia en el esclarecimiento de la homogeneidad espacial y en la conformación del bioma evocado en la pluralidad discursiva.

Un bioma, según Claude A. Villée, es una gran comunidad unitaria caracterizada por el tipo de plantas y de animales que alberga (87).
}

Esta biogeografía interesa a Robles en tanto que "evidencia la naturaleza agreste de las comunidades y, consecuentemente, su régimen social” (p. 88). De ahí que establezca la estructura ocupacional, las prácticas comerciales y el régimen alimentario del complejo discursivo de El Llano en Llamas a partir de esta isotopía biogeográfica.

Mi interés es otro. Si bien considero las figuras de referente animal como una isotopía, por su carácter repetitivo a lo largo de los cuentos, me interesa observar sobre todo la relación simbólica que se establece entre animales y personajes, y también otras funciones que cumplen las referencias a animales, como por ejemplo la creación de ambientes.

Un interés semejante se presenta en Arce Zumbado (1992), en donde se analiza el fenómeno de "zoonimización" en la novela Cleopatra Pérez de José Ortega Munilla. En esta obra, el uso de referencias a animales sirve para caracterizar al conjunto de personajes que se sitúan en el plano disfórico o negativo:

Se da una manifestación de la animalidad subyacente a la humanidad. Los personajes reciben atributos animalescos ya sea por nominación o por comparación. Es un procedimiento destructor de la persona porque se la degrada y se la anula como tal (87). 
En este trabajo de Arce Zumbado, que propone una interpretación de la estética naturalista, se concluye que esta se manifiesta en una retórica marginalizante, una de cuyas técnicas es

las clasificaciones que el narrador da a los personajes y que connotan características zoonímicas. La evaluación zoonímica permite percibir un mundo degradado por el vicio, la corrupción, la inmoralidad y esta degradación es característica fundamental de una retórica naturalista (95).

En Rulfo, la zoomorfización no es un recurso que divida el mundo del relato en dos planos eufórico (positivo) / disfórico (negativo), sino que cumple diversas funciones. Para comprenderlas mejor, cabe hacer una breve referencia a lo que he denominado en el título de este trabajo "fauna simbólica". Asumo con ello la premisa de que las referencias a animales simbolizan algo.

En este sentido, cabe recordar brevemente la discusión que Wellek y Warren (1974) hacen con respecto a la relación entre imagen, metáfora, símbolo y mito. Según estos teóricos, los cuatro términos se superponen y representan la convergencia de dos rectas: una referida a las sensaciones, las cuales asocian con las imágenes, y otra referida a las figuras o tropos, "al lenguaje indirecto, "oblicuo", que se expresa en metonimias y metáforas, comparando parcialmente mundos, precisando sus temas mediante traducciones a otros lenguajes" (221-2). En los cuentos de Rulfo encontramos representada esta convergencia: las imágenes de animales, por una parte, funcionan creando ambientes; las figuras, introducidas mediante metonimias, metáforas y símiles, establecen relaciones simbólicas de personaje-animal. No hay que olvidar, sin embargo, la advertencia de que "(1)a imagen puede darse como "descripción" o bien (...) como metáfora. Pero, ¿pueden ser simbólicas (...) las imágenes que no se brindan como metáforas?"(op.cit. p. 223-4); esto porque en muchas obras, la descripción de un ambiente puede ser a su vez una metáfora o un símbolo, tal es el caso de la selva del Chaco en la novela $E l$ Infierno Verde de José Marín Cañas. De tal modo que trazar una distinción tajante entre imagen, metáfora y símbolo bien podría ser una tarea imposible o al menos estéril.

Wellek y Warren se preguntan si imagen, metáfora y símbolo difieren en algún aspecto importante y concluyen que

A una "imagen" puede recurrirse una vez como metáfora, pero si se repite persistentemente, como presentación a la vez que como representación, se convierte en símbolo e incluso puede convertirse en parte de un sistema simbólico (o mítico) (225).

De acuerdo con esto, notaremos que algunas de las referencias a animales devienen en símbolos, por su persistencia, mientras que algunas otras constituyen imágenes que sirven un propósito puntual en determinado relato. En las conclusiones, trataremos de sistematizar desde esta perspectiva las múltiples referencias a animales que aparecen en los cuentos de Juan Rulfo.

\subsection{Macario}

Este cuento tiene como tema central "la locura como inocencia". Desde la primera oración, el narrador protagonista, Macario, se encuentra en relación sintagmática con las ranas: 
Estoy sentado junto a la alcantarilla aguardando a que salgan las ranas.

Además, como ocurre a menudo con la simbología animal en Rulfo, la relación personaje-animal viene desarrollada en las siguientes líneas:

Anoche, mientras estábamos cenando, comenzaron a armar el gran alboroto y no pararon de cantar hasta que amaneció, [y continúa]: Mi madrina también dice eso: que la gritería de las ranas le espantó el sueño.

Las ranas son protagónicas en la situación inicial del relato; sin embargo, su función esencial es, de nuevo por proceso metonímico, establecer una red de relaciones simbólicas a través del color:

Las ranas son verdes de todo a todo menos en la panza. Los sapos son negros. También los ojos de mi madrina son negros.

El tercer personaje, Felipa, es introducido también mediante una figura animal: "Felipa tiene los ojos verdes como los ojos de los gatos".

De este modo vemos que los tres personajes del relato, Macario, su madrina y Felipa, son identificados y relacionados mediante tres símiles referidos a animales, los cuales permiten establecer los siguientes tres sintagmas:

Macario se asocia a las ranas, que son verdes.

La madrina se asocia a los sapos, que son negros.

Felipa se asocia a los gatos, que tienen los ojos verdes.

De este modo, por medio de un juego metonímico, Macario se acerca a Felipa a través del verde y se contrapone a la madrina.

Además del simbolismo animal utilizado en la caracterización de los tres personajes, el protagonista aparece rodeado de una serie de animales, en particular de insectos:

Me acuesto sobre mis costales y en cuanto siento alguna cucaracha caminar con sus patas rasposas por mi pescuezo, le doy un manotazo y la aplasto (...) Las cucarachas truenan como saltapericos cuando uno las destripa. Los grillos no sé si truenen. A los grillos nunca los mato. (...) Tal vez haya más grillos que cucarachas aquí entre las arrugas de los costales donde yo me acuesto. También hay alacranes (...)

Buena parte del relato está concentrada en esta relación entre el narrador protagonista y los animales citados, cerrándose el relato con el regreso a las ranas, a la situación inicial del relato:

Ahora estoy junto a la alcantarilla esperando a que salgan las ranas.

\subsection{Nos han dado la tierra}

El tema de este relato es la opresión y la impotencia del campesino. También aquí, la situación inicial está protagonizada por animales; en este caso se trata de un animal simbólico y esencial en la obra de Rulfo, los perros: 
Después de tantas horas de caminar sin encontrar ni una sombra de árbol, ni una semilla de árbol, ni una raíz de nada, se oye el ladrar de los perros.

Aquí el ladrido de los perros funciona como metonimia de los hombres, pues donde se escuchan perros es porque hay una población. A lo largo de los relatos, el ladrido de los perros tiene esta relación metonímica con el poblado. En este cuento la relación se hace explícita:

Uno ha creído a veces, en medio de este camino sin orillas, que nada habría después. (...) Pero sí hay algo. Hay un pueblo. Se oye que ladran los perros...

En este cuento, las imágenes de animales sirven para describir el ambiente del llano, ya sea por indicación de su ausencia:

"No hay ni conejos ni pájaros", "pero nada se levantará de aquí. Ni zopilotes”, "(el llano) servirá para correr yeguas. - ¿Cuáles yeguas?”

o de su presencia:

"A no ser unos cuantos huizaches trespeleques ..." "Se le resbalan a uno los ojos al no encontrar cosa que los detenga. Solo unas cuantas lagartijas..."

El desenlace del cuento está marcado por la aparición de otro animal que pasa a ser protágonico en la situación final: la gallina de Esteban. Esta gallina tiene una relación simbólica con el personaje Esteban, es su compañía, probablemente lo único que tiene, por eso se la trajo con él.

Otros animales que aparecen en este cuento, no con carácter protagónico aquí (pero sí en otros cuentos), son los caballos. El hombre sobre el caballo es uno de los símbolos más persistentes del campesino mexicano, el arreador.

\subsection{La cuesta de la comadres}

El tema del relato es la maldad, el asesinato. Los hermanos Torricos aparecen asociados a los cuervos, como gente mala que era:

... después de que murieron los Torricos nadie volvió más por aquí (...) Los únicos que no dejaron nunca de venir fueron los aguaceros (...) De vez en cuando, también, venían los cuervos, volando muy bajito y graznando fuerte...

Cuando los Torricos desaparecían de la Cuesta de las Comadres,

la gente sacaba de las cuevas del monte sus animalitos y los traía a amarrar en sus corrales. Entonces se sabía que había borregos y guajolotes (...) Y uno oía en la madrugada que cantaban los gallos...

Estos animales domésticos están asociados a la gente del pueblo con connotación positiva.

El cuento cierra con una metáfora que relaciona directamente a los Torricos con los zopilotes: 
... por el rumbo donde tiré a Remigio se levantaba una gran parvada de zopilotes...

\subsection{Es que somos muy pobres}

En este cuento, cuyo tema es el destino, el determinismo, el animal fundamental, que desencadena la tragedia con su muerte, es la vaca de Tacha. La vaca simboliza el futuro de Tacha, la hermana del narrador protagonista:

... mi papá, con muchos trabajos, había conseguido a la Serpentina, desde que era una vaquilla, para dársela a mi hermana, con el fin de que ella tuviera una capitalito y no se fuera a ir de piruja como lo hicieron mis otras dos hermanas...

Hay una relación metonímica entre la vaca como fuente de leche y alimento, calificada positivamente, con los senos de las hermanas "puntiagudos y altos y medio alborotados para llamar la atención", que vienen a ser la perdición de ellas y, por el mal destino, también de Tacha, que perdió su vaca:

... y los dos pechitos de ella se mueven de arriba abajo, sin parar, como si de repente comenzaran a hincharse para empezar a trabajar por su perdición.

\subsection{El hombre}

El tema aquí es la venganza. Este relato se inicia con una relación simbólica entre el personaje y la referencia genérica de animal; tal como se aprecia en el siguiente símil:

Los pies del hombre se hundieron en la arena, dejando una huella sin forma, como si fuera la pezuña de algún animal.

Varias entidades son asociadas con la serpiente, con lo cual se establece una relación simbólica entre el objeto y este animal:

Lo vio brillar [el machete] como un pedazo de culebra sin vida.

Camina y da vueltas sobre sí mismo [el río]. Va y viene como una serpentina enroscada sobre la tierra verde.

Te esperaré un mes, despierto de día y de noche, sabiendo que llegarías a rastras, escondido como una mala víbora.

Los pájaros, concretamente, chachalacas, se usan para dar ambientación y señalar el paso del tiempo.

[El hombre] vio venir las chachalacas. La tarde anterior se habían ido siguiendo el sol....

Pasaron más parvadas de chachalacas, graznando con gritos que ensordecían.

Como en otros cuentos, los animales domésticos son elementos positivos del relato:

Uno vive remontado en el cerro, sin más trato que los borregos, y los borregos no saben de chismes. 
Y el relato cierra, metonímicamente, haciendo alusión a esos mismos animales:

Soy borreguero y no sé de otras cosas.

Se desprende de las dos últimas citas, que el campesino, como arriero, está simbolizado por el borrego.

\subsection{En la madrugada}

El tema en este cuento es la ira que conduce al asesinato, desencadenada por el patrón, que valora al animal por encima del sirviente. Aparte de la relación simbólica que se establece con el becerro golpeado, las referencias a animales sirven para crear ambiente:

... el viejo Esteban viene montado en el lomo de una vaca arreando el ganado de la ordeña. Se ha subido allí para que no le brinquen a la cara los chapulines. Se espanta los zancudos con el sombrero...

Las imágenes de pájaros también contribuyen al ambiente: "una golondrina cruzó las calles", "una lechuza grazna en el hueco de los árboles."

Cuando el protagonista (el viejo) está castigando sin compasión al becerro, don Justo (el patrón) aparece y golpea al viejo. Se entabla la lucha y muere el patrón.

Aquí se establece un paralelismo entre la situación que se describe entre la vaca y el becerro, por una parte:

(Esteban a la vaca): míralo y lengüetéalo (...) estás ya por parir y todavía te encariñas con ese grandulón. [Al becerro:] Saboréalas nomás, que ya no son tuyas (...) Y le dio de patadas cuando vio que mamaba de las cuatro tetas;

y por otra, la situación que se desencadena entre el patrón y la sobrina, relación presentada como incestuosa.

\subsection{Talpa}

El fervor religioso y el remordimiento son los temas de este cuento, en el cual impacta la forma en que va girando la perspectiva narratoria. Aunque hay pocas figuras relativas a animales, los símiles son claves en el relato, porque sirven para calificar como impura la conducta de Natalia y su cuñado; esta impureza también está asociada simbólicamente con la enfermedad de Tanilo. Esta apreciación se hace manifiesta en las siguientes figuras:

Nunca había sentido que fuera más lenta y violenta la vida como caminar entre un amontonadero de gente; igual que si fuéramos un hervidero de gusanos apelotonados bajo el sol, retorciéndonos entre la cerrazón del polvo que nos encerraba a todos en la misma vereda y nos llevaba como acorralados.

...aquella cosa que era mi hermano Tanilo Santos; aquella cosa tan llena de cataplasmas y de hilos oscuros de sangre que dejaba en el aire, un olor agrio como de animal muerto. 
Tal vez los dos tenemos muy cerca el cuerpo de Tanilo, tendido en el petate enrollado; lleno por dentro y por fuera de un hervidero de moscas azules que zumbaban como si fuera un gran ronquido que saliera de la boca de él.

El cuento, como es frecuente, cierra con una imagen animal:

... Natalia y yo echamos piedras encima para que no lo fueran a desenterrar los animales del cerro.

\subsection{El Llano en Llamas}

El cuento trata sobre las correrías de los revolucionarios cristeros contra las tropas del gobierno. La figura del perro tiene especial relevancia, asociada a uno de los personajes apodado "la perra"; el epígrafe, tomado de un corrido popular, también alude a este animal: "Ya mataron a la perra pero quedan los perritos..."

Aquí aparece una espesa fauna que sirve sobre todo para dar el ambiente de los cerros: "[estábamos] como iguanas", "volaron los totochilos, esos pájaros colorados...", "En seguida las chicharras...", "Pasaron los pájaros, bandadas de tordos...", "como si hubiéramos caído en un enjambre de chapulines", "[subimos] a gatas, como tejones espantados por la lumbre", "como si la lengua se nos hubiera hecho bola como la de los pericos", "cuando se oían los aullidos de los coyotes", "ya no había caballos, solo estaba un burro trasijado".

A partir de aquí, las menciones de animales revelan el cambio de acción: de los enfrentamientos guerreros en el cerro al escondite sedentario en el cañón del Tozín:

habíamos empezado a criar gallinas y (buscábamos) venados", "nos ocupábamos en destazar una vaca", "era como el bramido de un toro", "agarrándonos como a gallinas acorraladas", "corriendo como mulas brutas.

El caballo, como símbolo propio de ese ambiente, es persistente en el relato:

Los coyotes se oían más cerquita cuando llegamos al corral donde habíamos encerrado la caballada.

Pedro Zamora pasó por delante haciendo galopar aquel macho barcino y chaparrito que era el mejor animal que yo había conocido. Y detrás de él, nosotros, en manada, agachados sobre el pescuezo de los caballos.

... y en las ancas de su caballo venía atravesado un montón de rifles...

-En el camino conseguiremos caballos -nos dijo.

-Epa, tú, Pitasio, métele espuelas a ese caballo.

Finalmente, el narrador protagonista aparece zoomorfizado mediante el apodo "Pichón".

\section{9 ¡Diles que no me maten!}

El tema aquí es la venganza obligada del padre. De nuevo el móvil del primer crimen tiene que ver con los animales: 
Don Lupe Terreros (...). Al que él, Juvencio Nava, tuvo que matar por eso: por ser el dueño de la Puerta de Piedra y que, siendo también su compadre, le negó el pasto para sus animales.

Un novillo es el elemento clave que desencadena la tragedia:

Y me mató un novillo.

El relato cierra también con una imagen alusiva a los animales, en donde metafóricamente se asocia el coyote con la crueldad del hombre:

Te mirarán a la cara y creerán que no eres tú. Se les afigurará que te ha comido el coyote, cuando te vean con esa cara tan llena de boquetes por tanto tiro de gracia como te dieron.

\subsection{Luvina}

El tema es la desolación, la insignificancia de la vida. Aquí la fauna se presenta escuálida, simbolizando el ambiente desolado del cerro Luvina. Solo se mencionan los comejenes, y en términos genéricos, las bestias, los animales; también está presente el caballo. Un símil significativo es el que presenta a los murciélagos, en asociación simbólica con los habitantes de Luvina:

Era como un aletear de murciélagos en la oscuridad (...) De murciélagos de grandes alas que rozaban el suelo. Me levanté y se oyó el aletear más fuerte, como si la parvada de murciélagos se hubiera espantado y volara hacia los agujeros de las puertas. Entonces caminé de puntitas hacia allá (...). Me detuve en la puerta y las vi. Vi a todas las mujeres de Luvina con su cántaro al hombro, ...

También aquí, el cierre del cuento vuelve a aludir a los comejenes, animales asociados simbólicamente con el ambiente de Luvina:

El hombre que miraba a los comejenes se recostó sobre la mesa y se quedó dormido.

\subsection{La noche que lo dejaron solo}

El tema del relato es el destino, la suerte. La imagen animal aquí es poco notoria, aunque siempre aparece en el "apretado golpetear de pezuñas sobre el seco tepetate del camino". Es una metonimia de los arrieros que van pasando cerca del protagonista, el "muchachito".

\subsection{Acuérdate}

Se trata como tema el determinismo. Como en el cuento anterior, hay pocas imágenes animales, sin embargo el protagonista Urbano Gómez aparece asociado simbólicamente con el perro mediante un símil: 
... y allí los vieron: (...) al Urbano mandándole un culatazo tras otro con el máuser, sin oír lo que le gritaba la gente, rabioso como perro del mal.

También su prima "la Arremangada" se asocia al coyote mediante un símil:

Y después a ella, que salió haciendo pucheros (...), hasta que ya en la puerta soltó el llanto; un chillido que se estuvo oyendo toda la tarde como si fuera un aullido de coyote.

\subsection{No oyes ladrar a los perros}

Este cuento trata de la maldad del hijo y el amor del padre. Aquí el elemento animal esencial es el de los perros, como metonimia de la población a la que se desea llegar, tal como se explicó en el análisis de "Nos han dado la tierra".

\subsection{Anacleto Morontes}

Este cuento, cuyo tema es el engaño religioso, es el único que se permite una gota de humor. La asociación simbólica con los animales es la de las diez viejas que son comparadas con mulas. Con esta imagen se abre el relato:

¡Viejas, hijas del demonio! Las vi venir a todas juntas, en procesión. Vestidas de negro, sudando como mulas bajo el mero rayo del sol.

Esta comparación se acentúa con el nombre de la población de donde vienen: Amula.

Otra asociación importante es la de las gallinas, que metafóricamente remiten a las viejas, y los dos conejos, que simbolizan a Anacleto Morones y su yerno Lucas Lucatero, narrador protagonista.

\subsection{El día del derrumbe}

En este cuento, que tiene como tema la corrupción política, no hay imágenes de animales, excepto por las referencias a las comilonas de guajolote y venado. Sin embargo, parece tener intención simbólica el nombre de la canción que tocaron los músicos en el festín que los pobladores de Tuxcacuexco se vieron obligados a darle al gobernador, quien los visitó después del terremoto:

Entraron sonándole duro al arpa y a la tambora, haciendo tatachum, chum, chum, con los platillos, arreándole fuerte y con ganas al Zopilote mojado.

Pareciera una alusión a la burla que hizo el gobernador a los habitantes de Tuxcacuexco, que quedaron como "zopilotes mojados" después de la visita del gobernador; este con su comitiva se aprovechó de la gran fiesta y dio un lindo discurso, pero nada más. 


\subsection{La herencia de Matilde Arcángel}

El tema del cuento es la maldad del padre y la bondad del hijo. Aquí, de nuevo un animal tiene papel protagónico, ya que un caballo causa la ruina de uno de los protagonistas, Euremio Cedillo hijo. El desencadenamiento de la tragedia se presenta en el cuento así:

(Matilde Arcángel) Después engordó. Tuvo un hijo. Luego murió. La mató un caballo desbocado.

En la situación final, los caballos vuelven a tener relevancia: "Todos venían montados en sus bestias", "Salió de su casa a caballo", "Luego el trote de'caballos". El relato se cierra con las tres entidades protagonistas: el caballo, el hijo vivo y el padre muerto:

\footnotetext{
Y a poco rato vi venir a mi ahijado Euremio montado en el caballo de mi compadre Euremio Cedillo. Venía en ancas, con la mano izquierda dándole duro a su flauta, mientras que con la derecha sostenía, atravesado sobre la silla, el cuerpo de su padre muerto.
}

\section{Conclusión}

Dado el abundante uso de las imágenes de animales como recurso literario para reforzar los contenidos de cada cuento, he intentado delinear algunas relaciones simbólicas entre animales y personajes. A partir de lo señalado en este trabajo preliminar, podemos enumerar algunas generalidades sobre este recurso de la narrativa de Rulfo:

Conforme con el ambiente rural, los cerros, los poblados lejanos, fantasmales, la fauna doméstica está asociada al pueblo y está presentada como elemento positivo; son las vacas, las gallinas, los becerros, etc.

Por su persistencia, el caballo constituye un símbolo separado, con su propio significado; asociado tanto al arriero como al bandido; es parte del hombre pero también es capaz de causar su muerte.

Los perros, casi siempre presentados así, como colectivo, son un marcador de población cercana; para el perseguido, para el que se esconde y busca refugio en una población, o para el que busca ayuda, el ladrido de los perros representa una esperanza (como en "No oyes ladrar a los perros"). Pero el perro también a veces es descalificador, cuando se compara con un individuo.

La fauna del cerro suele ser rastrera (culebras, lagartijas), huidiza; es utilizada para dar ambiente. Los pájaros, también crean ambiente, pero tienen más funciones: crean expectativa, muestran el paso del tiempo, a veces simbolizan a un personaje, etc.

Las imágenes relacionadas con insectos evocan complejas relaciones simbólicas con los personajes y se utilizan también para crear ambiente.

\section{Bibliografía}

Amoretti, María. 1992. "Por una dialógica de la cultura. Aportes de Bajtín al pensamiento contemporáneo". En Revista de Filología y Lingüística de la Universidad de Costa Rica XVIII (2): 7-8. 
Anderson Imbert, Enrique. 1964. Historia de la Literatura Hispanoamericana. Vol. II. 4a. ed. México: Fondo de Cultura Económica.

Arce Zumbado, Dora María. 1992. Onomástica y Marginalidad en la Novela Cleopatra Pérez de José Ortega Munilla: Hacia una Interpretación de la Estética Naturalista. Tesis de Licenciatura: Universidad de Costa Rica.

Greimas, A.J. 1976. Semántica Estructural. Madrid: Gredos.

1970. "Elementos para una teoría de la interpretación del relato mítico". En Roland Barthes et al. Análisis Estructural del Relato. Buenos Aires: Editorial Tiempo Contemporáneo.

Jara, Carla Victoria. 1987. "Elegía de un Madrigal' o la muerte de la poesía”. En Revista de Filología y Lingüística de la Universidad de Costa Rica. XIII (1): 63-9.

Menton. Seymour. 1964. El Cuento Hispanoamericano. Vol. II. México: Fondo de Cultura Económica.

Morales, Carlos. 1985. El Café de las 4. San José: Editorial Costa Rica.

Robles Mohs, Ivonne. 1983. La Pluralidad Discursiva y el Universo Homogéneo de El Llano en Llamas. Tesis de licenciatura: Universidad de Costa Rica.

Rulfo, Juan. 1953. Pedro Páramo y El Llano en Llamas. Barcelona: Editorial Planeta.

Sainz de Robles, F.C. 1949. Diccionario de la Literatura. Vol. II, Madrid: Aguilar.

Varios. 1985. Homenaje a Juan Rulfo. Cuadernos Hispanoamericanos. No. 421.

Wellek, René y Austin Warren. 1974. Teoría Literaria. 4ta. ed. Madrid: Gredos. 